\title{
Superfícies fotocatalíticas de titânia em substratos cerâmicos. Parte I: Síntese, estrutura e fotoatividade
}

\section{(Photocatalytic surfaces of titania on ceramic substrates. Part I: Synthesis, structure and photoactivity)}

\author{
J. Feltrin ${ }^{1,2}$, M. N. Sartor ${ }^{1}$, A. De Noni Jr. ${ }^{2,3}$, A. M. Bernardin ${ }^{3}$, D. Hotza ${ }^{1}$, J. A. Labrincha ${ }^{4}$ \\ ${ }^{1}$ Programa de Pós-Graduação em Ciência e Engenharia dos Materiais, Universidade Federal de Santa \\ Catarina, Florianópolis, $S C$ \\ ${ }_{2}^{2}$ Instituto Maximiliano Gaidzinski, R. Edson Gaidzinski 352, Cocal do Sul, SC 88845-000 \\ ${ }^{3}$ Universidade do Extremo Sul Catarinense, Av. Universitária 1105, Bairro Universitário, \\ Criciúma, SC 88806-000 \\ ${ }^{4}$ Departamento de Engenharia Cerâmica e do Vidro, Universidade de Aveiro, 3810-193 Aveiro, Portugal
}

\begin{abstract}
Resumo
A fotocatálise é um processo de oxidação avançada capaz de transformar uma grande variedade de poluentes orgânicos tóxicos em substâncias inofensivas em condições ambientes. Porém, a utilização do dióxido de titânio na fase anatase em produtos cerâmicos é limitada devido à transformação para fase rutilo em temperaturas superiores a $400{ }^{\circ} \mathrm{C}$. As pesquisas apontam caminhos promissores para inibir a formação da fase rutilo através da introdução de dopantes na estrutura do semicondutor. Neste trabalho, foi realizada uma revisão dos principais aspectos encontrados na literatura especializada sobre fotocatálise com dióxido de titânio, em particular a relação entre estrutura química e atividade fotocatalítica.

Palavras-chave: fotocatálise, dióxido de titânio, superfícies cerâmicas.
\end{abstract}

\begin{abstract}
Photocatalysis has been considered as an advanced oxidation process capable of transforming a large variety of toxic organic pollutants into harmless substances at ambient conditions. However, the use of titanium dioxide as anatase in ceramic products is limited due to transformation to rutile at temperatures higher than $400{ }^{\circ} \mathrm{C}$. The studies show promising ways for inhibiting the formation of rutile through the introduction of dopants in the semiconductor structure. This work is a review of the main aspects found in specialized literature with photocatalytic titanium dioxide, particularly the relationship between chemical structure and photocatalytic activity.
\end{abstract}

Keywords: photocatalysis, titanium dioxide, ceramic surfaces.

\section{INTRODUÇÃO}

O dióxido de titânio ou titânia $\left(\mathrm{TiO}_{2}\right)$ [1] é um dos mais importantes pigmentos brancos produzidos, sendo sua produção mundial em torno de 4,5 milhões de ton/ano [2]. Existem três tipos de polimorfos no óxido de titânio: o rutilo, a anatase e a brookita; os dois últimos apresentam menor utilização comercial $[1,3,4]$. Os principais usos estão em tintas e revestimentos (57\%), plásticos (24\%), papéis e tintas de impressão (13\%). Há também uma ampla gama de utilizações menores, porém importantes como produtos farmacêuticos, alimentos e cosméticos $[2,3]$. $\mathrm{O}$ alto índice de refração dos cristais de rutilo, que leva ao seu maior poder opacificante e superior estabilidade exterior, é a principal razão para seu uso preferencial em relação à anatase. A anatase é usada apenas em algumas aplicações específicas, devido à sua tonalidade azulada, sua habilidade de agir como branqueador óptico ou sua baixa abrasividade
[5]. O dióxido de titânio é considerado de importância estratégica e está sendo exaustivamente estudado nas últimas cinco décadas, por ser um dos fotocatalisadores mais eficazes para oxidação à temperatura ambiente de muitos produtos orgânicos perigosos e também como um composto atraente para conversão de energia solar [6]. A ação fotocatalítica do dióxido de titânio pode ser aplicada em diversos campos como purificação do ar, da água, como fungicida, bactericida e viricida e como agente esterilizador [7]. Nos últimos anos, a atividade fotocatalítica do $\mathrm{TiO}_{2}$ tem-se tornado cada vez mais atrativa a nível industrial, quando comparada com as técnicas tradicionais usadas para o tratamento de águas e para a despoluição do ar [7]. Como matéria-prima cerâmica, a titânia se comporta como um óxido intermediário [8] e é utilizada na composição dos vidros, esmaltes para porcelanas e metais, contudo este óxido pode gerar uma opacidade amarelada que não é adequada para o uso em esmaltes brancos $[8,9]$. Os 
cristalitos da titânia formados durante o processo de queima geram opacidade [10], no entanto, impurezas ( $\mathrm{Fe}, \mathrm{Cr}$, etc.) presentes nas matérias-primas utilizadas podem interferir na cor final [11]. Alguns estudos têm tratado a relação entre tamanho e a forma do cristalito da titânia com a refletância e a cor resultante, identificando as fases rutilo e anatase com as partículas aciculares do rutilo, produzidas em temperaturas mais altas e com um tempo maior de queima, e as partículas redondas de anatase, formadas em uma etapa anterior. A cor azul se associa as partículas menores e redondas da anatase e a cor amarela que se forma posteriormente se associa a dissolução das partículas de anatase em partículas maiores rutilo. A mudança de azul para amarelo corresponde a um aumento importante da razão de rutilo/anatase [9]. Conforme a quantidade de titânia adicionada aos esmaltes, obtemos diferentes acabamentos superficiais: $1-4 \%$ de titânia opacifica os esmaltes com elevada quantidade de álcalis e sem chumbo; teores de 5\% de titânia produzem uma opacificação completa e quantidades superiores a $10 \%$ a superfície adquire efeito mate devido a formação de grandes cristais de rutilo [12]. Esta incorporação aumenta notavelmente o índice de refração e melhora a resistência química dos vidros formados como também a resistência mecânica [8]. Em geral a fase polimórfica anatase é preferida devido a sua alta atividade fotocatalítica, porém esta fase não é estável a altas temperaturas e sua aplicação em cerâmica é limitada. A nucleação da titânia (de $425^{\circ} \mathrm{C}$ a $460{ }^{\circ} \mathrm{C}$ ) e a velocidade de crescimento $\left(\right.$ de $620^{\circ} \mathrm{C}$ a $720{ }^{\circ} \mathrm{C}$ ) controlam as fases cristalinas e polimórficas resultantes. Além disso, a temperatura apresenta um efeito maior que o tempo na viscosidade do vidro e na velocidade de crescimento para os esmaltes opacificados com titânia [9]. A nucleação da anatase é um fenômeno mássico e a nucleação do rutilo se produz na interface entre as partículas adjacentes de frita. A diminuição dos cristalitos de anatase em relação aos cristais superficiais de rutilo indica que a conversão de anatase em rutilo é um processo de maturação, mais que uma transformação de fase [9].

Neste contexto, procura-se mostrar os diversos aspectos envolvidos na fotocatálise numa série de dois artigos, iniciando-se pelo processo de fabricação de dióxido de titânio e temas relacionados com as aplicações em cerâmica, estruturas química e cristalina, estabilização térmica e finaliza-se com os processos de deposição e tratamento térmico.

\section{PRODUÇÃO INDUSTRIAL E SÍNTESE EM LABORATÓRIO}

Aproximadamente $91 \%$ da produção mundial de titânio é obtida da ilmenita $\left(\mathrm{FeTiO}_{3}\right)$, de ocorrência mais comum, enquanto que o restante vem do rutilo $\left(\mathrm{TiO}_{2}\right)$, que é mais escasso. As reservas de titânio na forma de ilmenita e rutilo totalizaram em 2010 aproximadamente $650 \mathrm{Mt}$, sendo mais da metade dessas reservas concentradas em três países: China (30,77\%), Austrália (15,38\%) e Índia (13,08\%). Os maiores produtores mundiais de titânio foram: Austrália $(21,1 \%)$,
África do Sul (19,5\%), Canadá $(10,9 \%)$ e China $(9,4 \%)$. A DuPont Titanium Technologies é a maior fabricante de dióxido de titânio [13]. As reservas brasileiras de ilmenita e rutilo são de $\sim 3 \mathrm{Mt}$ e representam apenas $0,5 \%$ das reservas mundiais. O Brasil é o maior produtor da América Latina, tendo produzido em 2010 aproximadamente $2 \%$ da produção mundial de titânio, destinada majoritariamente à fabricação de tintas, esmaltes e vernizes [13]. A produção da titânia é obtida a partir de depósitos primários ou secundários. Nos depósitos primários, o rutilo é raramente encontrado em concentrações economicamente aproveitáveis, ocorrendo associados ao mineral de ferro. Nos depósitos secundários, ocorrem em áreas de praias, ou próximas às mesmas [14].

Comercialmente o dióxido de titânio é produzido por dois processos: sulfatação e cloretação. $\mathrm{O}$ processo sulfato foi o primeiro a ser usado comercialmente [15] é uma operação industrial complexa de múltiplos estágios [5]. Leucoxênio e rutilo não podem ser usados nesse processo por serem insolúveis ou parcialmente solúveis. $\mathrm{O}$ minério bruto de titânio, a ilmenita, ou escória de titânio [15] é reagido com o ácido sulfúrico quente, que resulta em sulfato de titanila, [5] sulfato ferroso e férrico. As equações A, B e $\mathrm{C}$ e a Fig. 1 representam, respectivamente, as etapas de digestão, hidrólise e calcinação do processo sulfato [5].

$$
\begin{aligned}
& \mathrm{FeOTiO}_{2}+2 \mathrm{H}_{2} \mathrm{SO}_{4} \rightarrow \mathrm{TiOSO}_{4}+\mathrm{FeSO}_{4}+2 \mathrm{H}_{2} \mathrm{O} \\
& \mathrm{TiOSO}_{4}+2 \mathrm{H}_{2} \mathrm{O} \rightarrow \mathrm{TiO}(\mathrm{OH})_{2}+\mathrm{H}_{2} \mathrm{SO}_{4} \\
& \mathrm{TiO}(\mathrm{OH})_{2} \rightarrow \mathrm{TiO}_{2}+\mathrm{H}_{2} \mathrm{O}
\end{aligned}
$$

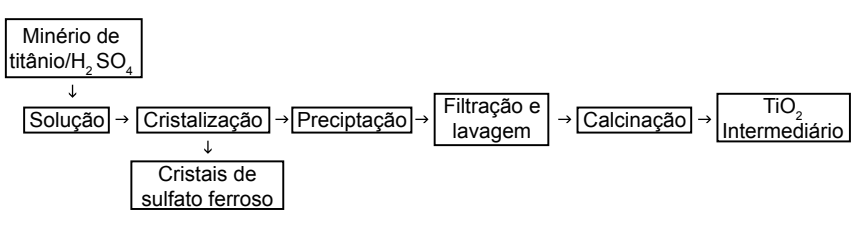

Figura 1: Processo Sulfato. Fonte: Adaptado [2]. [Figure 1: Sulfate Process. Source: Adapted [2].]

No entanto, o interesse por esse processo tem diminuído em função de ser produzido um pigmento de qualidade inferior para a maioria das aplicações. Além disso, há problemas ambientais decorrentes da grande quantidade de rejeito gerado na forma de sulfato de ferro: cada tonelada de dióxido de titânio obtida pelo processo via sulfato gera 7 (1:7) toneladas de resíduos, enquanto pelo processo de cloretação a relação é de 1:1 [15].

No processo cloreto o rutilo mineral (natural ou sintético) é reagido com cloro gasoso em presença de coque para formar tetracloreto de titânio líquido $\left(\mathrm{TiCl}_{4}\right)$. As equações $\mathrm{D}$ e E e a Fig. 2 representam, respectivamente, as etapas de cloração e oxidação do processo cloreto [5].

$$
\begin{aligned}
& \mathrm{TiO}_{2}+\mathrm{C}+2 \mathrm{Cl}_{2} \rightarrow \mathrm{TiCl}_{4}+\mathrm{CO}_{2} \\
& \mathrm{TiCl}_{4}+\mathrm{O}_{2} \rightarrow \mathrm{TiO}_{2}+2 \mathrm{Cl}_{2}
\end{aligned}
$$




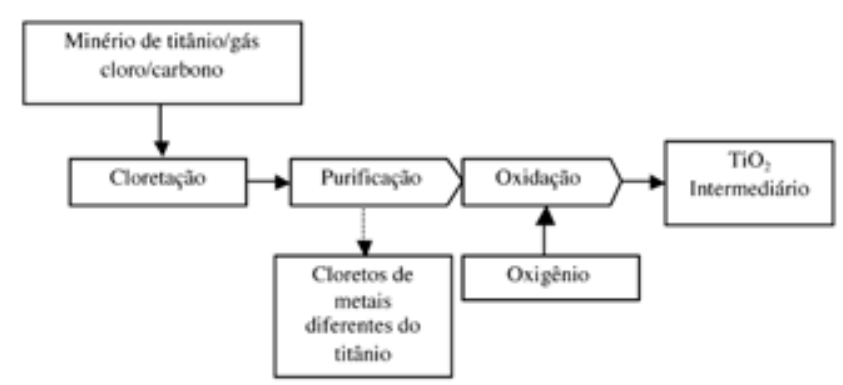

Figura 2: Processo Cloreto. Fonte: Adaptado [2].

[Figure 2: Chloride Process. Source: Adapted [2].]

O produto pode ser calcinado para remoção dos cloretos residuais e os dois processos podem ser finalizados com moagem para controle da distribuição granulométrica $(0,2$ a $0,4 \mu \mathrm{m})$ e tratamento superficial [16]. Aproximadamente 1 ton de cloreto é necessária para produzir de 5 a 6 ton de titânia. O consumo de cloreto depende da quantidade de ferro contido no rutilo, e a ilmenita não pode ser usada nesse processo, devido ao seu elevado teor de ferro, o que implicaria a formação de grande quantidade de rejeito na forma de cloreto de ferro. Observa-se uma tendência mundial pela utilização do processo por cloretação. Atualmente, cerca de $60 \%$ do dióxido de titânio produzido no mundo é proveniente das usinas de cloretação [15]. O dióxido de titânio também pode ser sinterizado em laboratório. A técnica mais utilizada é sol-gel a partir de um precursor como tetraisopropóxido de titânio [17-22] ou tetracloreto de titânio [23, 24]. A utilização do tetraisopropóxido de titânio (Ti-i-pr, $\left.\operatorname{Ti}\left(\mathrm{OCH}\left(\mathrm{CH}_{3}\right)_{2}\right)_{4}\right)$ como precursor é mais referenciada, na qual sóis aquosos de Ti-i-pr são obtidos a partir da peptização e hidrólise de Ti-i-pr usando água destilada. A sequência das etapas está apresentada na Fig. 3.

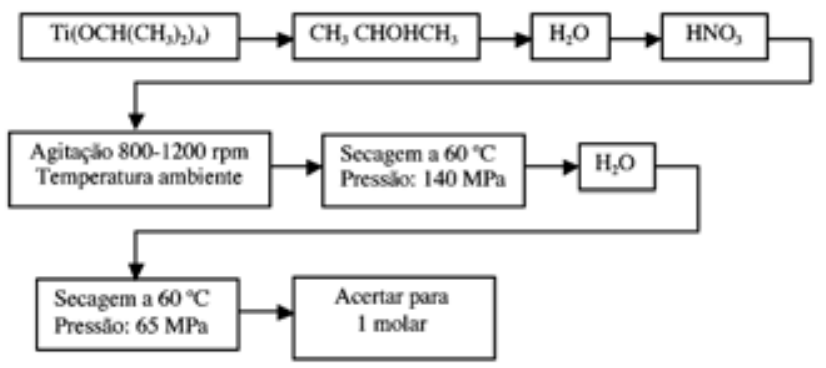

Figura 3: Obtenção de titânia em laboratório a partir do precursor (Ti-i-pr, $\left.\mathrm{Ti}\left(\mathrm{OCH}\left(\mathrm{CH}_{3}\right)_{2}\right)_{4}\right)$.

[Figure 3: Obtaining titania in laboratory from the precursor (Tii-Pr, $\left.\left.\mathrm{Ti}\left(\mathrm{OCH}\left(\mathrm{CH}_{3}\right)_{2}\right)_{4}\right) \cdot\right]$

A escolha do tipo de $\mathrm{TiO}_{2}$, comercial ou sintetizado quimicamente em laboratório, deve ser avaliada. O $\mathrm{TiO}_{2}$ sintetizado em laboratório oferece as vantagens de controle da estequiometria [25], do tamanho e da forma das nanopartículas (quando utilizado um surfactante) [26], e obtenção de um produto homogêneo [25]. Além disso, geralmente o $\mathrm{TiO}_{2}$ sintetizado pode apresentar uma área superficial maior que as referências comerciais e, consequentemente, maior atividade fotocatalítica. Por fim, é possível também otimizar e controlar a cristalinidade e a estabilidade da fase [27, 28]. No entanto, para a titânia sintetizada, há algumas desvantagens, incluindo custo elevado dos precursores, longo tempo de processamento a presença de carbono como impureza [25]. A opção em usar a titânia comercial está relacionada pela praticidade. O $\mathrm{TiO}_{2}$ comercial mais utilizado em fotocatálise é da EvonikDegussa com nome comercial Aerosil ${ }^{\circledR}$ P25 [3].

Na Tabela I podem-se observar diferentes métodos de obtenção, composições e superfícies específicas da titânia tanto sintetizadas quanto comerciais.

\section{ESTRUTURA QUÍMICA}

No $\mathrm{TiO}_{2}$, cada átomo de titânio está rodeado por 6 átomos de $\mathrm{O}$ e cada átomo de $\mathrm{O}$ por 3 átomos de Ti. Portanto, cada íon de titânio é envolvido por um octaedro distorcido de oxigênio (Fig. 4) [25].

A transição eletrônica pode ser representada na Fig. 5 pela espectroscopia de fotoelétrons de raios X (XPS) e espectros de fotoluminescência combinados com a teoria do orbital atômico e a teoria do campo cristalino [30].

Os elétrons localizados na órbita mais externa do átomo (elétrons de valência) são responsáveis pela ligação dos átomos. Entre as bandas de elétrons, há uma com o maior nível de energia (órbita do elétron mais distante do núcleo) que é a banda de valência; a banda externa é referida como a banda de condução. A energia entre a banda de valência e a banda de condução é chamada de O gap é como um obstáculo que os elétrons devem saltar para se tornarem livres. A quantidade de energia necessária para saltar é a energia de band gap. Elétrons que saltam na banda de condução, os elétrons de condução, é que podem mover-se livremente [30,31].

Quanto ao fornecimento de radiação, cada semicondutor tem uma energia mínima necessária para que o elétron seja promovido da banda de condução para a banda de valência $\left(\mathrm{E}_{b g}\right)$, associada a um comprimento de onda [32]. O comprimento de onda necessário para ativar o catalisador deve ser igual ou inferior ao calculado pela equação de Planck:

$$
\lambda=\frac{\mathrm{hc}}{\mathrm{E}_{\mathrm{bg}}}
$$

na qual $\mathrm{E}_{\mathrm{bg}}$ é a energia de band gap (eletron-volt: $\mathrm{eV}$ ) ou energia de ativação (no $\mathrm{TiO}_{2}=3,2 \mathrm{eV}$ ), $h$ a constante de Planck $\left(4,136 \times 10^{-15} \mathrm{eV} . \mathrm{s}\right), \mathrm{c}$ a velocidade da luz $(2,998 \times$ $\left.10^{8} \mathrm{~m} / \mathrm{s}\right)$, e $\lambda$ o comprimento de onda $(\mathrm{nm})$.

Quando rutilo e anatase são irradiados com luz de 413 $\mathrm{nm}$ e $388 \mathrm{~nm}$, respectivamente, os elétrons da banda de valência sobem à banda de condução. Ao mesmo tempo são criados buracos (electron hole) positivos correspondentes ao número de elétrons que saltaram para a banda de condução [33].

A banda de valência do óxido de titânio é composta pelo 
Tabela I- Condições de síntese da titânia e sua respectiva área superficial.

[Table I - Conditions of synthesis of titania and its respective surface area.]

\begin{tabular}{|c|c|c|c|c|c|}
\hline Origem & Identificação & Método de Síntese & Composição em Massa (\%) & $\mathrm{S}_{\mathrm{BET}}\left(\mathrm{m}^{2} \mathrm{~g}^{-1}\right)$ & Ref. \\
\hline \multirow{6}{*}{$\begin{array}{l}\text { Sintetizado } \\
\text { em laboratório }\end{array}$} & $\mathrm{H} 1$ & Hidrotermal & \multirow{6}{*}{ Anatase } & 179 & \multirow{6}{*}[27]{} \\
\hline & $\mathrm{H} 2$ & Hidrotermal & & 102 & \\
\hline & N1 & Hidrotermal & & 95 & \\
\hline & $\mathrm{N} 2$ & Hidrotermal & & 72 & \\
\hline & N3 & Hidrotermal & & 65 & \\
\hline & N4 & Hidrotermal & & 54 & \\
\hline Evonik & P25 & Cloretação & Anatase $(75 \%)+$ rutilo $(25 \%)$ & 50 & $\begin{array}{l}{[7,19,36,41,44,} \\
49,58,62,71-76]\end{array}$ \\
\hline $\begin{array}{c}\text { Sintetizado } \\
\text { em laboratório }\end{array}$ & TNTs & Hidrotermal & Trititanato (TNT) & 157,9 & {$[58]$} \\
\hline $\begin{array}{l}\text { Ishihara } \\
\text { Sangyo } \\
\text { Kaisha } \\
\end{array}$ & ST 01 & --- & --- & 302 & {$[6]$} \\
\hline \multirow{3}{*}{$\begin{array}{c}\text { Sintetizado } \\
\text { em laboratório }\end{array}$} & $\mathrm{TiO}_{2}$ & Sol gel & Anatase + utilo & 7 & \multirow{3}{*}[18]{} \\
\hline & $\mathrm{TiO}_{2}+\mathrm{Zn}$ & $\begin{array}{l}\text { Sol gel e dopado } \\
\text { com Zn }\end{array}$ & Anatase & 41 & \\
\hline & $\mathrm{TiO}_{2}+\mathrm{Fe}$ & $\begin{array}{l}\text { Sol gel e dopado } \\
\text { com Fé }\end{array}$ & Anatase & 15 & \\
\hline Aldrich & Anatase & --- & Anatase $(99,9 \%)$ & 48 & [44] \\
\hline \multirow{3}{*}{ Cristal Global } & PC50 & \multirow{3}{*}{ Sulfatação } & Anatase (>97\%) & 50 & \multirow{11}{*}{ [71] } \\
\hline & PC10 & & Anatase (> 99\%) & 10 & \\
\hline & S5-300A & & Anatase $(\sim 20 \%)$ & 280 & \\
\hline Evonik & TN90 & Cloretação & Anatase + rutilo & 90 & \\
\hline $\begin{array}{c}\text { GmbH } \\
\text { Huntsmann }\end{array}$ & AHR & --- & Anatase & 11 & \\
\hline Fluka & Anatase & --- & Anatase & 9 & \\
\hline \multirow{5}{*}{ Tayca } & JA1 & \multirow{5}{*}{---} & Anatase & 9 & \\
\hline & TKP101 & & Anatase & 300 & \\
\hline & TKS201 & & Anatase & 241 & \\
\hline & TKS203 & & Anatase & 214 & \\
\hline & TKP103 & & Anatase & 280 & \\
\hline Cristal Global & PC 500 & Sulfatação & Anatase $(82-86 \%)$ & $320-330$ & {$[62,71]$} \\
\hline \multirow{2}{*}{$\begin{array}{l}\text { Prolabo VWR } \\
\text { Fontenay- } \\
\text { sous-bois }\end{array}$} & Anatase & & Anatase & 10,7 & \multirow[b]{2}{*}[57]{} \\
\hline & Rutilo & --- & Rutilo & 1,39 & \\
\hline Warwick & Kronos & --- & Anatase & --- & \\
\hline Quimialmel & CR 826 & --- & Rutilo & --- & {$[77]$} \\
\hline Quimialmel & $\mathrm{CH}$ & --- & Anatase-Rutilo & --- & \\
\hline
\end{tabular}

orbital $2 \mathrm{p}$ do oxigênio, enquanto a banda de condução é composta pelo orbital 3d do titânio. Num semicondutor com um largo gap, os elétrons na banda de valência não podem saltar para a banda de condução. No entanto, se a energia é aplicada externamente, os elétrons na banda de valência podem subir para banda de condução. Consequentemente, os elétrons geram muitos buracos. Isso é equivalente ao movimento de elétrons da ligação orbital ao orbital 


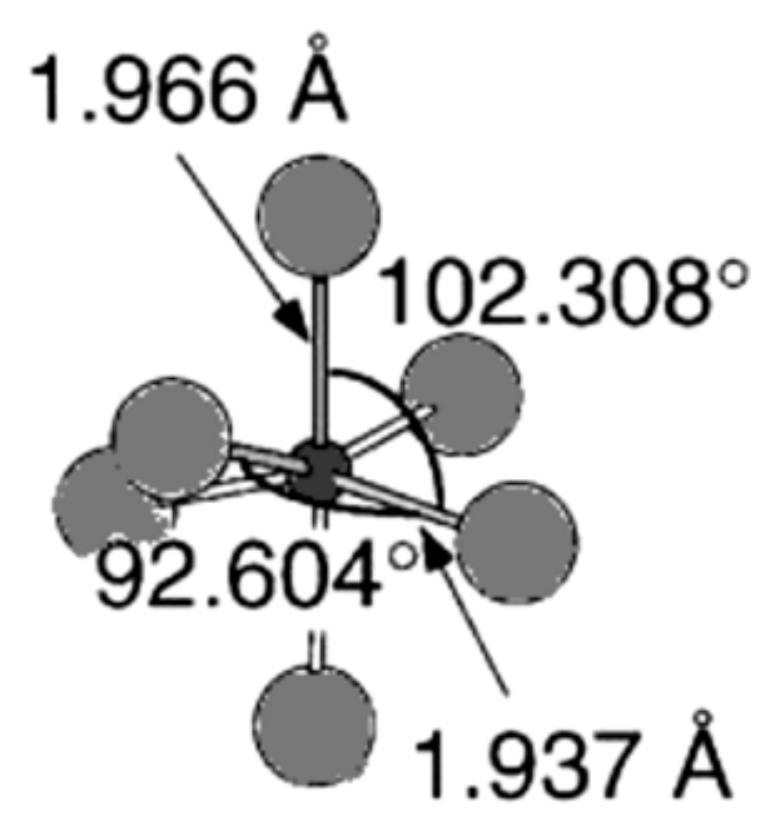

Figura 4: Arranjo molecular do $\mathrm{TiO}_{2}$, átomo de Ti rodeado por 6 átomos de O. Fonte: Adaptado [29].

[Figure 4: $\mathrm{TiO}_{2}$ molecular arrangement, Ti atom surrounded by 6 O atoms. Source: Adapted [29].]

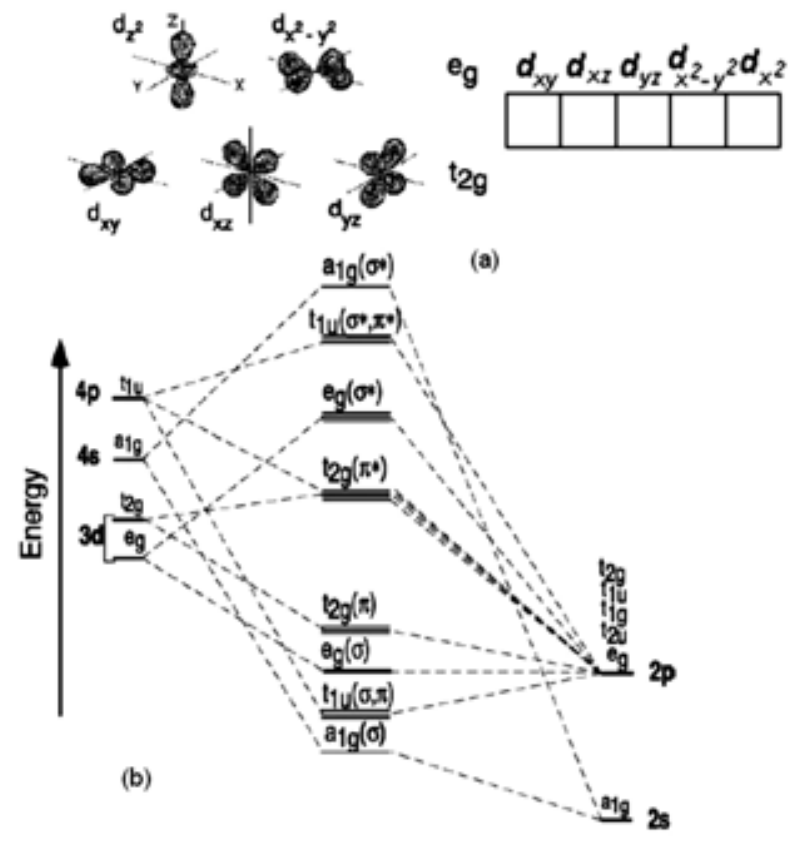

Figura 5: (a) Lóbulos do orbital d e divisão em e $\mathrm{e}_{\mathrm{g}}$ e $\mathrm{t}_{2 \mathrm{~g}}$; (b) Diagrama de nível de energia do $\mathrm{TiO}_{2}$. Adaptado de [29].

[Figure 5: (a) Orbital lobes split into $e_{g}$ and $t_{2 g^{\circ}}$ (b) Energy level diagram of $\mathrm{TiO}_{2}$. Adapted from [29].]

antiligante. Em outras palavras, o estado fotoexcitado de um semicondutor é geralmente instável e pode facilmente quebrar. O óxido de titânio, por outro lado, mantém-se altamente estável $[20,25]$, mesmo quando é fotoexcitado. Essa é uma das razões que pelas quais o $\mathrm{TiO}_{2}$ torna-se um excelente fotocatalisador. Os três fatores a seguir se relacionam com a estrutura da banda dos semicondutores e

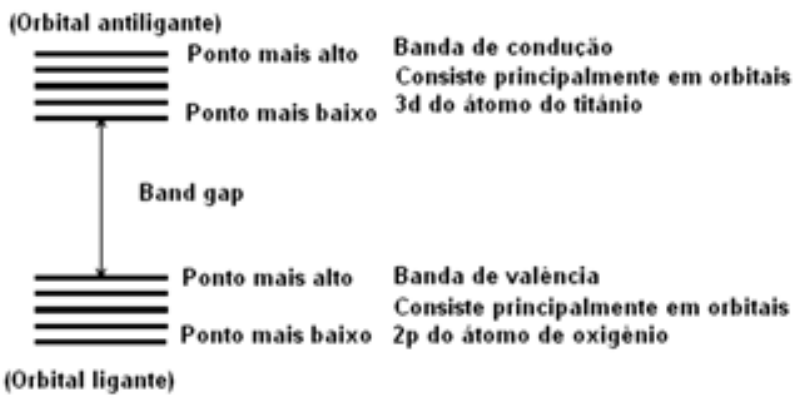

Figura 6: Estruturas das bandas de valência e de condução do $\mathrm{TiO}_{2}$ Adaptado [33, 34].

[Figure 6: Structures bands valence and conduction of $\mathrm{TiO}_{2}$. Adapted [33, 34].]

tem influência na fotocatálise [33]: energia da banda, posição do ponto mais baixo na banda de condução, e posição do ponto mais alto da banda de valência.

Também podem ser relacionados outros parâmetros ligados ao desempenho do $\mathrm{TiO}_{2}$ como fotocatalisador, tais como fase cristalina, área superficial específica, tamanho de partícula/morfologia e condições de tratamento térmico [7].

Nas reações fotocatalíticas a energia da banda determina principalmente qual comprimento de onda de luz é mais eficaz. A posição do ponto mais alto na banda de valência é o principal determinante do poder de decomposição oxidativa do fotocatalisador, a Fig. 6 apresenta a estrutura das bandas de valência e de condução do $\mathrm{TiO}_{2}$ [33].

\section{ESTRUTURA CRISTALINA}

Existem três tipos de estruturas cristalinas do óxido de titânio: o rutilo, a anatase e a brookita. As duas primeiras apresentam estruturas cristalinas tetragonais (volume espacial $\mathrm{P} 4_{2} / \mathrm{mnm}$ e $\mathrm{Z}=2$ para o rutilo; $\mathrm{I}_{1} /$ amd e $\mathrm{Z}=4$ para a anatase) enquanto a brookita apresenta estrutura ortorrômbica (volume espacial Pbca e Z=8) [23, 25, 35, 36]. A Fig. 7 apresenta os três polimorfos do $\mathrm{TiO}_{2}$ e as estruturas cristalinas.

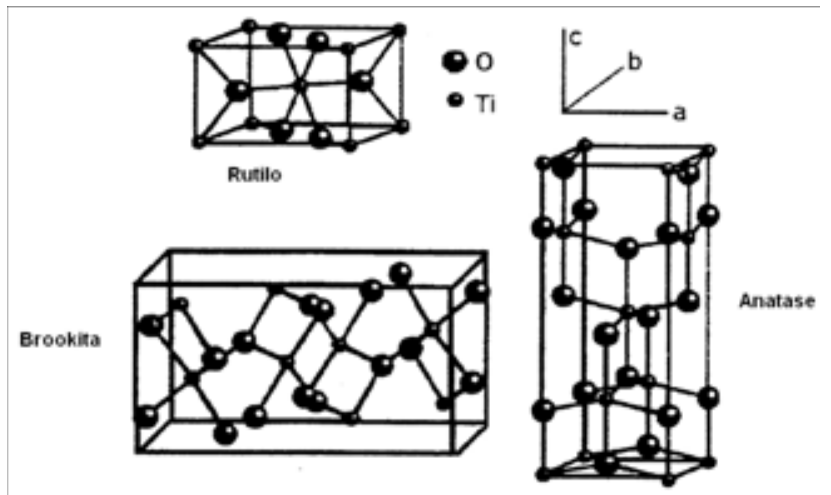

Figura 7: Disposição geométrica das estruturas cristalinas: rutilo, anatase e brookita. Fonte: [37].

[Figure 7: Geometric arrangement of crystalline structures: rutile, anatase and brookite. Source: [37].] 
Tabela II - Propriedades físicas de rutilo, anatase e brookita. Fonte: [25, 38, 40, 41]. [Table II - Physical properties of rutile, anatase and brookite. Source: [25, 38, 40, 41].]

\begin{tabular}{cccc}
\hline Propriedades Físicas & Rutilo & Anatase & Brookita \\
\hline Densidade específica $\left(\mathrm{g} / \mathrm{cm}^{3}\right)$ & 4,13 & 3,79 & 3,99 \\
Dureza (Mohs) & 6,5 & 5 & 5,75 \\
Volume molecular calculado a partir da célula & 62,430 & 136,270 & 257,630 \\
unitária $\left(\AA^{3}\right)$ & 3,02 & 3,20 & 2,96 \\
Energia do bang gap $(\mathrm{eV})$ & $1,949(4)$ & $1,937(4)$ & $1,870-2,040$ \\
Ti-O comprimento da ligação $(\AA)$ & $1,980(2)$ & $1,965(2)$ & $77,0^{\circ}$ \\
& $81,2^{\circ}$ & $77,7^{\circ}$ & $105^{\circ}$ \\
Ti-O-Ti ângulo da ligação $(\AA)$ & $90,0^{\circ}$ & $90,0^{\circ}$ & 0,9184 \\
Parâmetro a da célula unitária $(\mathrm{nm})$ & 0,4584 & 0,3782 & 0,5447 \\
Parâmetro b da célula unitária $(\mathrm{nm})$ & 0,4584 & 0,3782 & 0,5145 \\
Parâmetro c da célula unitária $(\mathrm{nm})$ & 0,2953 & 0,9502 & \\
\hline
\end{tabular}

Enquanto rutilo é a fase estável, tanto anatase quanto brookita são metaestáveis [1]. A fase termodinamicamente estável tem relação com o tamanho do cristalito: anatase é estável para tamanhos de cristalito inferiores a $11 \mathrm{~nm}$; brookita, entre 11 e $35 \mathrm{~nm}$; e rutilo, para tamanhos superiores a $35 \mathrm{~nm}[38,39]$.

As diferenças de estrutura e arranjo cristalino resultam num conjunto de propriedades distintas para cada fase (Tabela II).

O óxido de titânio absorve a luz e quando esta atinge um nível de energia maior do que o gap, os elétrons pulam para a banda de condução criam buracos positivos na banda de valência. Tanto anatase como rutilo absorvem apenas os raios ultravioletas [3, 42], sendo o valor do gap de $3,0 \mathrm{eV}$ para o rutilo e $3,2 \mathrm{eV}$ para a anatase $[23,25]$. O fotocatalisador é uma substância que, depois de ser irradiada pela luz, pode induzir a uma reação química de tal forma que a substância em si não será consumida [43]. O rutilo pode absorver os raios que estão ligeiramente mais próximos à faixa de luz visível, e supostamente seria mais adequado para uso como fotocatalisador. No entanto, a anatase apresenta maior atividade fotocatalítica. A fase brookita é complexa, tem um volume maior de células (a célula unitária é composta por 8 unidades de $\mathrm{TiO}_{2}$ ) [25], além de ser difícil de ser sintetizada [1].

Algumas razões que contribuem para o melhor desempenho da anatase são a área superficial elevada [23, 44] uma alta densidade de sítios ativos de adsorção, além de uma recombinação mais lenta e maior mobilidade dos elétrons $[1,23]$. Por outro lado, o rutilo apresenta baixa capacidade de adsorção de $\mathrm{O}_{2}[1,45]$. O rutilo, com um menor band gap, tem uma foto-resposta que se estende um pouco para a região da luz visível, mas tende a mostrar altas taxas de recombinação das cargas. Normalmente, a recombinação de portadores de carga rápida (elétrons e buracos) compete com o aprisionamento de carga e transferência e, consequentemente, limita a eficiência quântica dos processos fotocatalíticos [46].

\section{ATIVAÇÃO FOTOCATALÍTICA}

A band gap da anatase é $3,2 \mathrm{eV}$ e equivale a um comprimento de onda de $388 \mathrm{~nm}$. A absorção de raios na faixa ultravioleta promove reações fotocatalíticas [33]. A taxa de reação fotocatalítica depende muito da absorção da radiação do fotocatalisador. Estudos revelaram um aumento na taxa de degradação com o aumento da intensidade de luz [47].

No óxido de titânio, a absorção dos raios ultravioletas ocorre com um comprimento de onda de $388 \mathrm{~nm}$ ou menor, como $254 \mathrm{~nm}$, que tem um nível maior de energia. Esse efeito pode ser utilizado em lâmpadas germicidas, sendo os raios UV são absorvidos pelo DNA de organismos vivos formando dímeros de pirimidina, e danificando assim o DNA. $\mathrm{O} \mathrm{TiO}_{2}$ como fotocatalisador não requer raios ultravioletas, que podem ser perigosos aos seres humanos. Ele também permite que reações iniciem pelos raios ultravioletas com comprimentos de onda relativamente longos contidos na luz solar e emitidos por lâmpadas fluorescentes [33].

Apenas $5 \%$ da luz solar total irradiada tem energia suficiente para causar efetiva fotossensibilização. Além disso, a perda de energia devido à reflexão da luz, transmissão e perda de energia como o calor é inevitável

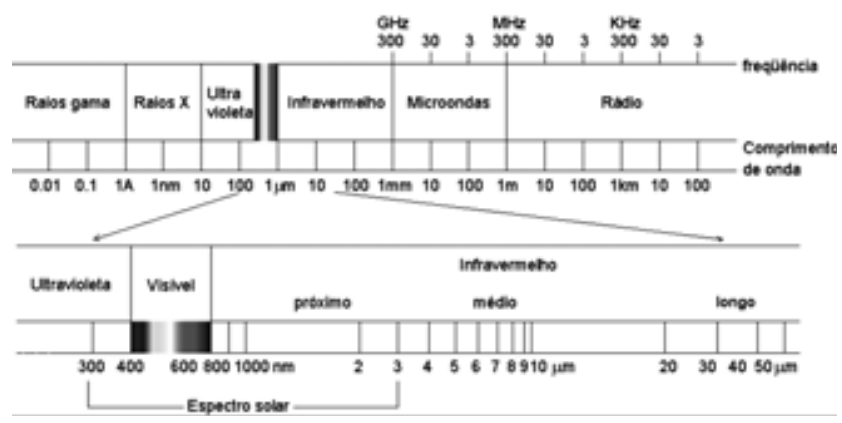

Figura 8: Espectro eletromagnético. Fonte: [48].

[Figure 8: Electromagnetic spectrum. Source: [48].] 
na fotocatálise [47]. O efeito fotoelétrico depende dos fótons, mas numa primeira aproximação não dependerá da intensidade da luz, isso significa que a luz de um ambiente interno pode ser suficiente para ajudar a purificar o ar ou para manter as paredes limpas, porque as quantidades de poluentes são tipicamente pequenas. Assim, em uma sala razoavelmente bem iluminada, com uma intensidade de luz total de aproximadamente $10 \mu \mathrm{Wcm}^{-2}$, com energia superior a do gap do $\mathrm{TiO}_{2}$ de aproximadamente $1 \mu \mathrm{Wcm}^{-2}$, seria de intensidade suficiente para decompor uma camada de hidrocarbonetos de $\sim 1 \mu \mathrm{m}$ de espessura (com eficiência quântica de 25\%) a cada hora [33].

A radiação eletromagnética é transmitida através do espaço, a luz visível e o calor são as formas mais facilmente observadas e sentidas de radiação, mas ela pode ser encontrada em muitas outras formas, conforme se observa na Fig. 8 que representa o espectro eletromagnético [48].

A região do espectro eletromagnético entre 300 e 3000 $\mathrm{nm}$, denominada de espectro solar, representa o conjunto de radiações geradas pelo Sol [48]. O Sol emite energia em praticamente todos os comprimentos de onda do espectro eletromagnético permeados pelas diversas linhas de absorção.

A radiação ultravioleta (UV) é a parte do espectro eletromagnético referentes aos comprimentos de onda menores que $400 \mathrm{~nm}$. Comumente se classifica a UV em três tipos ou bandas: UVA, UVB e UVC. A camada de ozônio na estratosfera absorve alguns desses tipos de radiação ultravioleta, mas não todos [48].

A fotocatálise tem emergido como um processo de oxidação avançada (POA) para a descontaminação da água $[24,42,49]$ juntamente com a remoção de micro-organismos como uma alternativa ao tratamento convencional de água potável, bem como para a produção de água ultrapura para aplicações farmacêuticas [50], compostos corantes [7, 51], degradação de poluentes do ar, na obtenção de superfícies auto limpantes $[52,53]$ na esterilização, e até mesmo na terapia do câncer $[7,33]$ devido à geração de espécies oxidantes fortes.

A titânia é muito estudada devido a suas propriedades fotocatalíticas [54], ou seja, é capaz de oxidar os poluentes transformando-os em espécies químicas inócuas como o gás carbônico e a água. A titânia gera radicais hidroxila $\left(\mathrm{OH}^{*}\right)$ que são agentes altamente oxidantes [45, 47]. Outras espécies como e- $\mathrm{O}_{2}^{-}$e $\mathrm{HO}_{2}{ }^{-}$também podem ser geradas durante os processos fotocatalíticos e reagir com os poluentes [36].

Um POA pode ser dividido em sistemas homogêneos e heterogêneos, podendo gerar radicais hidroxila com ou sem radiação ultravioleta. Nos sistemas homogêneos, a oxidação ocorre numa única fase, utilizando como reagentes oxidantes: ozônio e/ou peróxido de hidrogênio, ou ainda o reagente de Fenton (solução de peróxido de hidrogênio e um catalisador de ferro) como geradores de radicais na presença ou ausência de radiação luminosa. Nos sistemas heterogêneos, a catálise utiliza fótons e está baseada na irradiação de um catalisador sólido, geralmente um semicondutor, que pode ser realizada em fase gasosa ou líquida [55]. Neste estudo, o foco é apenas a fotocatálise heterogênea, utilizando o $\mathrm{TiO}_{2}$ como catalisador sólido.

Fujishima em 1963 descobriu o fenômeno da fotocatálise na Universidade de Tóquio. Quando expôs um eletrodo de dióxido de titânio em uma solução aquosa sob luz de intensidade forte, bolhas de ar emergiram a superfície. Quando cessada a luz, as bolhas cessavam também. Seus estudos mostraram que a água foi decomposta em hidrogênio e oxigênio. [25, 54] Assim, a fotocatálise havia sido descoberta e a reação foi chamada de efeito HondaFujishima. Desde então, o titânio vem sendo alvo de muitos estudos [25, 54]. Nos anos 80, a equipe de Fujishima empregou a fotocatálise para tratamento de poluentes ambientais, principalmente na área de desinfecção e desodorização do ar. Uma das pesquisas consistiu na produção de um revestimento para as paredes e pisos da sala de cirurgia de hospitais. Os resultados demonstraram que a concentração de bactérias nas superfícies e no ar foi reduzida drasticamente, portanto o óxido de titânio pode ser usado como um material para revestimentos antibactericidas e na limpeza dos sistemas de ar [54]. Em 1995, o Instituto de Pesquisa de Toto, no Japão, permitiu ampliar os conhecimentos sobre as possíveis aplicações da fotocatálise. Foi descoberto que gotas de água se espalhavam e perdiam a sua tensão superficial quando depositadas sobre vidro coberto com dióxido de titânio. Atualmente, materiais baseados na super-hidrofilicidade são considerados autolimpantes, podem ser utilizados em espelhos retrovisores de carros e como revestimentos nos exteriores de edifícios [54].

Quando a luz é absorvida pelo óxido de titânio, (absorção de 1 fóton de energia, hv 3,2 eV) [30] dois portadores: os elétrons ( $\left.\mathrm{e}^{-}\right)$e os buracos positivos $\left(\mathrm{h}^{+}\right)$são formados (Fig. 9) $[7,34,43,56,57]$. Nas substâncias comuns, elétrons e buracos positivos se recombinam rapidamente. No entanto, na anatase elas se recombinam mais lentamente. A percentagem de recombinação tem um grande efeito sobre a eficiência fotocatalítica.

A geração de pares elétrons (e) buraco (h) pode ser representada por [61]:

$$
\operatorname{TiO}_{2} \stackrel{\text { hv }(300-400 \mathrm{~nm})}{\longrightarrow} \mathrm{h}^{+}+\mathrm{e}^{-}
$$

Uma das características notáveis do óxido de titânio é seu forte poder oxidativo relacionado com os buracos positivos, que é maior que o poder redutor dos elétrons na banda de condução [35]. A superfície de um fotocatalisador contém água absorvida. Quando essa água é oxidada pelos buracos positivos, são formados os radicais hidroxila $\left(\mathrm{OH}^{*}\right)$ [33].

$\mathrm{O}$ buraco $\mathrm{h}^{+}$reage com a água ou com o radical $\mathrm{OH}^{-}$para formar o radical hidroxila e $\mathrm{H}^{+}[41,61]$ :

$$
\begin{aligned}
& \mathrm{h}^{+}+\mathrm{H}_{2} \mathrm{O} \longrightarrow \mathrm{OH}^{\cdot}+\mathrm{H}^{+} \\
& \mathrm{h}^{+}+\mathrm{OH} \longrightarrow \mathrm{OH}^{\cdot}
\end{aligned}
$$

Se o oxigênio está presente quando este processo ocorre, 


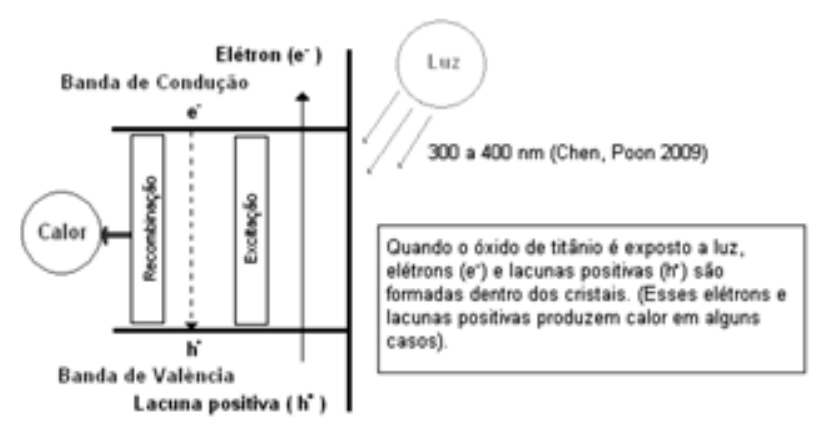

Figura 9: Formação dos buracos positivos e dos elétrons de condução após incidência da luz solar. Fonte: Adaptado [33, 34].

[Figure 9: Formation of positive holes and conduction electrons after sunlight incidence. Source: Adapted [33, 34].]

os radicais intermediários dos compostos orgânicos podem sofrer reações em cadeia e consumir o radical oxigênio. Nesse caso, a matéria orgânica eventualmente se decompõe, tornando-se dióxido de carbono e água [34, 43], que são os principais produtos finais, juntamente com $\mathrm{NO}_{x}$ e $\mathrm{HCl}$ para compostos orgânicos contendo nitrogênio e cloro [18]. Sob certas condições, compostos orgânicos podem reagir diretamente com os buracos positivos, resultando em decomposições oxidativas (Fig. 10).

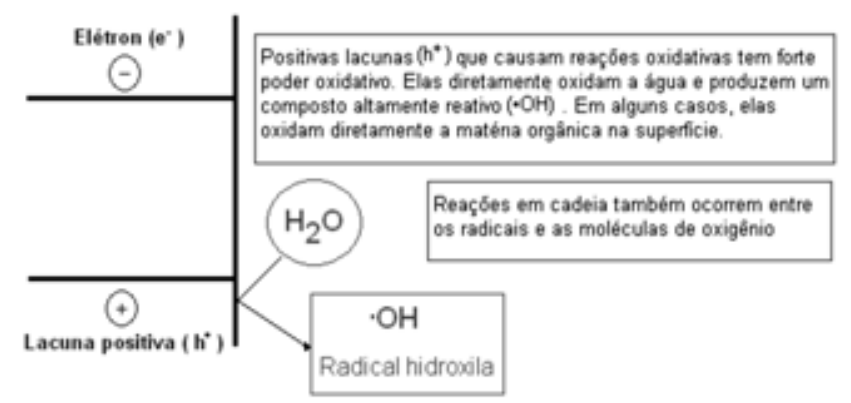

Figura 10: Mecanismo de oxidação. Fonte: Adaptado [33, 34].

[Figure 10: Oxidation mechanism. Source: Adapted [33, 34].]

$\mathrm{O}$ e` reage com o oxigênio molecular para formar o ânion superóxido [61]:

$$
\mathrm{e}^{-}+\mathrm{O}_{2} \longrightarrow \mathrm{O}_{2}^{--}
$$

A protonação do superóxido ocorre segundo [56]:

$$
\mathrm{O}_{2}^{--}+\mathrm{H}+\longrightarrow \mathrm{HOO}^{\circ}
$$

Para posteriormente haver a formação do superóxido de hidrogênio [56]:

$$
\begin{aligned}
& \mathrm{HOO}+\mathrm{e}^{-} \longrightarrow \mathrm{HO}_{2}^{-} \\
& \mathrm{HOO}-+\mathrm{H}^{+} \longrightarrow \mathrm{H}_{2} \mathrm{O}_{2}
\end{aligned}
$$

A adsorção preliminar de compostos orgânicos na superfície do catalisador é um requisito para a fotodegradação

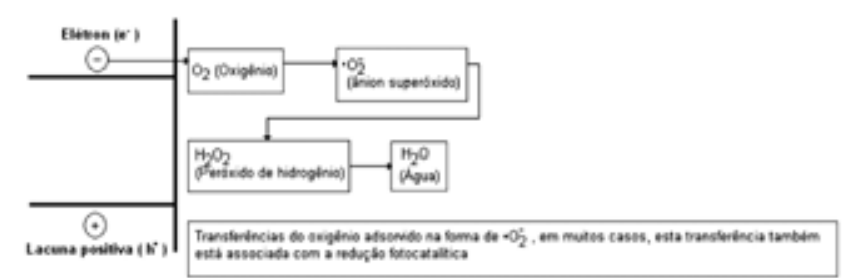

Figura 11: Mecanismo de redução. Fonte: Adaptado [33, 34].

[Figure 11: Reduction mechanism. Source: Adapted [33, 34].]

altamente eficiente [43, 58]. Enquanto isso, a redução do oxigênio contido no ar ocorre como uma reação de emparelhamento. $\mathrm{O}$ oxigênio é uma substância facilmente redutível e se estiver presente, a redução ocorre antes da formação dos radicais hidroxilas. A redução de oxigênio resulta no superóxido $\left(\cdot \mathrm{O}_{2}\right)$, cujos ânions contribuem para a reação oxidativa e formam o peróxido de hidrogênio (Fig. 11) [43].

Essencialmente, radicais hidroxila $(\bullet \mathrm{OH})$, buracos $\left(\mathrm{h}^{+}\right)$, íons superóxidos $\left(\mathrm{O}_{2}^{-}\right)$e radicais hidroperoxil $(\cdot \mathrm{OOH})$ atuam simultaneamente para oxidar uma grande variedade de poluentes orgânicos, incluindo compostos orgânicos voláteis (VOCs) e bioaerossóis [47]. Pode-se representar a reação geral de oxidação de poluentes orgânicos como [59]:

Orgânico $+\mathrm{O}_{2} \stackrel{\text { hv TiO}}{2} \underset{\mathrm{CO}_{2}}{\longrightarrow}+\mathrm{H}_{2}+$ ácidos minerais

O mecanismo de reação para a degradação fotooxidativa de muitos poluentes orgânicos com titânia foi extensivamente estudado. O número de intermediários na reação e a facilidade de decomposição dependem da natureza orgânica dos contaminantes [47].

A estequiometria geral para a oxidação de um hidrocarboneto clorado genérico a sua completa mineralização pode ser exemplificada por [54]:

$\mathrm{C}_{\mathrm{x}} \mathrm{H}_{\mathrm{y}} \mathrm{Cl}_{\mathrm{z}}+\left(\mathrm{x}+\frac{\mathrm{y}-\mathrm{z}}{4}\right) \cdot \mathrm{O}_{2} \stackrel{\mathrm{hv} \mathrm{TiO}_{2}}{\longrightarrow}$
$\mathrm{xCO}+\mathrm{zH}^{+}+\mathrm{zCl}-\left(\frac{\mathrm{y}-\mathrm{z}}{2}\right) \cdot \mathrm{H}_{2} \mathrm{O}$

Assim, a fotocatálise de um composto organoclorado gera $\mathrm{CO}_{2}$, água e íons cloro. Como a redução tende a ocorrer mais facilmente em matéria orgânica do que na água, quando a concentração de matéria orgânica é elevada, os buracos positivos são usadas nas reações oxidativas, reduzindo assim a taxa de recombinação transportada. O processo de transferência de elétrons para as moléculas de oxigênio na redução determina a velocidade da reação fotocatalítica, permitindo fácil transferência de elétrons com as moléculas de $\mathrm{O}$ e assim eficiência das reações fotocatalíticas pode ser melhorada [33].

Muitos semicondutores como $\mathrm{WO}_{3}, \mathrm{SnO}_{2}, \mathrm{CdS}, \mathrm{ZnO}$, $\mathrm{TiO}_{2}$, [44] e $\mathrm{ZnS}, \mathrm{Fe}_{2} \mathrm{O}_{3}$ podem agir como sensibilizadores em processos de oxidação e redução mediados pela luz devido à sua estrutura eletrônica (Fig. 12).

Entretanto, a combinação de fotoatividade e fotoestabilidade não é muitas vezes satisfeita. Como 


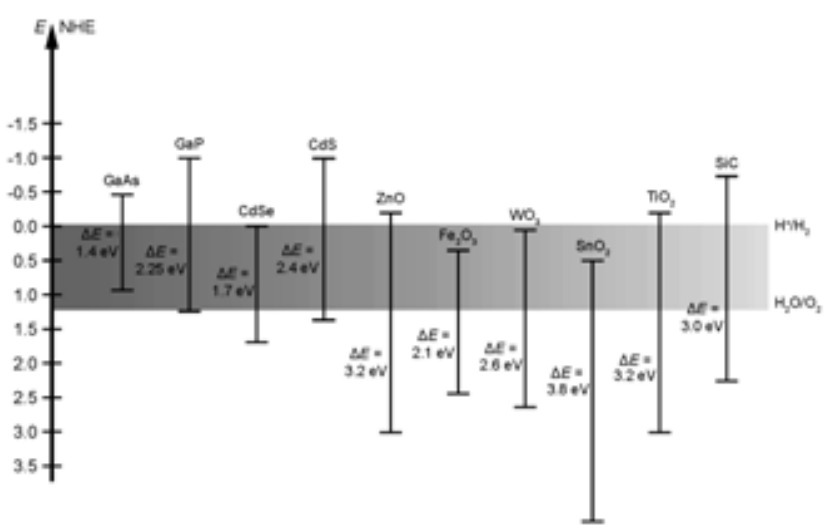

Figura 12: Posições de banda de vários semicondutores em contacto com a solução aquosa a $\mathrm{pH} 1$ e suas energias de banda proibida. A escala de energia é indicada em elétrons-volt usando o eletrodo de hidrogênio normal (NHE). Fonte: [60].

[Figure 12: Band positions of several semiconductors in contact with aqueous solution at pH 1 and their band gap energies. The energy scale is indicated in electron volts using the normal hydrogen electrode (NHE). Fonte: [60].]

exemplo, o semicondutor CdS, apesar de absorver radiação de até $510 \mathrm{~nm}$, sofre fotocorrosão quando irradiado, gerando $\mathrm{Cd}^{2+}$ e enxofre, inviabilizando sua utilização em processos de descontaminação [45]. Também o GaAs e o $\mathrm{PbS}$ não são estáveis para catálise em solução aquosa, sofrem fotodegradação e são tóxicos; $\mathrm{ZnO}$ é instável porque se dissolve facilmente em água; $\mathrm{Fe}_{2} \mathrm{O}_{3}, \mathrm{SnO}_{2}, \mathrm{WO}_{3}$ possuem um limite de banda de condução e necessitam de um sistema elétrico externo para decompor a água [25].

Entre os semicondutores, o $\mathrm{TiO}_{2}$ é o mais amplamente estudado devido principalmente: à̀ sua não toxicidade; fotoestabilidade, estabilidade química em uma ampla faixa de $\mathrm{pH}$ [45]. Sua atividade fotocatalítica é elevada em comparação com outros óxidos, e é compatível com materiais de construção tradicionais, como cimento, sem alterar qualquer desempenho original. [3] Além disso, é eficiente sob irradiação solar fraca em ambiente atmosférico, [53] e apresenta boa resistência a ácidos [23].

$\mathrm{O}$ uso de fotocatalisadores em materiais de construção começou a partir da década de 1990 . O $\mathrm{TiO}_{2}$ tanto pode servir como material fotocatalítico quanto como material estrutural, tem sido aplicado em materiais de construção exterior e materiais de decoração para interiores, tais como argamassa de cimento, telhas, blocos para pavimentação, vidro, tecido de PVC [53], papel, tintas, plásticos, entre outros [3].

$\mathrm{Na}$ maioria das pesquisas realizadas em fotocatálise o $\mathrm{TiO}_{2}$ utilizado está sob a forma de partículas em pó, muitas vezes dispersos em solução. Por outro lado, para muitas aplicações, a forma mais adequada é de um filme fino fortemente ligado a um substrato tal como vidro ou cerâmica. Vários fabricantes já estão produzindo vidros de autolimpeza e telhas cerâmicas que utilizam filmes finos de $\mathrm{TiO}_{2}$ para a decomposição e remoção de poluentes orgânicos $[44,61]$. A principal desvantagem de um revestimento de $\mathrm{TiO}_{2}$ é a diminuição de sua área de superfície específica em comparação ao pó. Porém, a eficiência fotocatalítica de filmes desenvolvidos pela técnica sol-gel e aplicados por dip-coating suportados em vidro tem mostrado propriedades comparáveis a pós comerciais [62].

\section{ESTABILIZAÇÃO TÉRMICA DA FASE ANATASE}

O tratamento térmico é uma prática comum e conveniente para manipular as propriedades físicas de um catalisador e para melhorar a atividade catalítica [43]. A estrutura cristalina, tamanho da partícula, forma das partículas (referente ao aspecto), área superficial, porosidade, atmosfera de queima, volume da amostra, taxa de aquecimento, tempo de imersão, impurezas, técnica de medição, microestrutura e outros afetam a atividade fotocatalítica da anatase não dopado [1]. O tratamento térmico é um processo importante para a imobilização do $\mathrm{TiO}_{2}$ [43] .

A cinética de transformação de anatase para rutilo $(\mathrm{A} \rightarrow \mathrm{R})$ pode ser alterada pela presença de impurezas/ dopantes. O processo pelo qual impurezas são introduzidas na estrutura do semicondutor é conhecido por dopagem [63]. As impurezas/dopantes geralmente são elementos metálicos ou não-metálicos que se alojam na estrutura do $\mathrm{TiO}_{2}$ na forma intersticial ou substitucional [40, 64]. A fotoatividade depende muito da presença dos dopantes, além da presença de substâncias como sílica amorfa na interface e/ou contornos de grão que tem grande influência sobre a taxa de transferência de massa, difusão e crescimento de cristalito da titânia [6]. O próprio processo de formação das fases via solução sólida favorece a inclusão de impurezas e o surgimento de defeitos [40,64].

A cinética de transformação da anatase em rutilo é afetada tanto pela natureza química dos íons como a forma como eles se encontram na estrutura. Íons intersticiais geralmente retardam a transformação enquanto que os íons substitucionais podem tanto retardar como acelerar. Utilizando dados da literatura é possível fazer uma estimativa dos efeitos dos potenciais dopantes usados como inibidores e promotores da transição de fase $\mathrm{A} \rightarrow$ R, Figs. 13 e 14 .

Dopantes observados experimentalmente a inibir a transformação $A \rightarrow R$

Dopantes observados experimentalmente a inibir a transformação $A \rightarrow R$ sob certas condições (misturas)

Dopantes previstos a inibir a transformação $A \rightarrow R$.
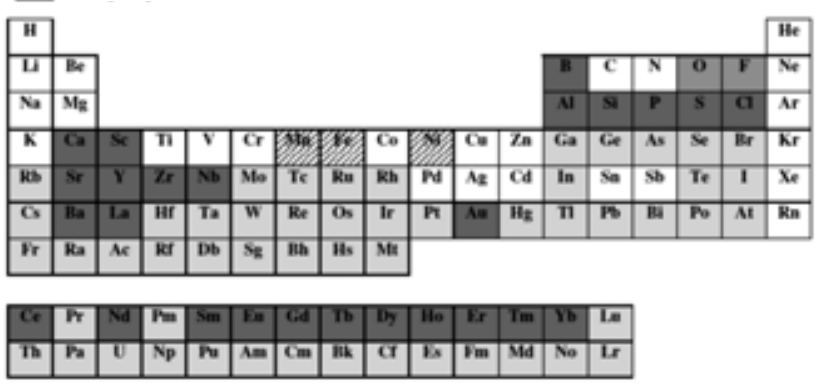

Figura 13: Relação de dopantes que inibem a transformação da fase $\mathrm{A} \rightarrow \mathrm{R}$. Fonte: [1].

[Figure 13: Ratio of dopant inhibiting phase transformation $A \rightarrow$ R. Source: [1].] 
Dopantes observados experimentalmente a inibir a transformação $A \rightarrow R$. Dopantes observados experimentalmente a inibir a transformação $A \rightarrow R$ sob certas condições (misturas).

Dopantes previstos a inibir a transformação $A \rightarrow R$.

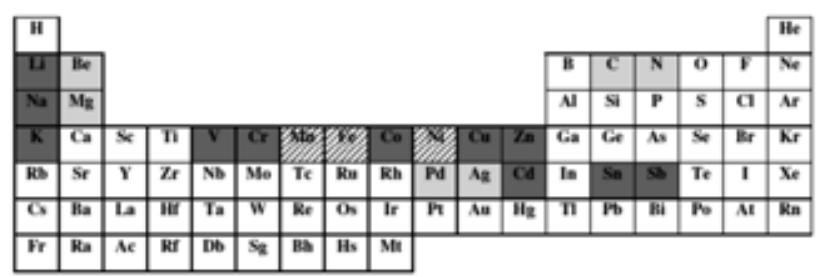

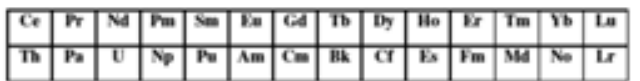

Figura 14: Relação de dopantes que promovem a transformação da fase $\mathrm{A} \rightarrow \mathrm{R}$. Fonte: [1].

Figure 14: Ratio of dopant promoting phase transformation $A \rightarrow$ R. Source: [1].]

A natureza das impurezas altera a estequiometria do $\mathrm{TiO}_{2}$, agindo diretamente sobre a concentração de oxigênio. Quando íons com valência menor do que 4 e com pequenos raios iônicos entram substitucionalmente na estrutura, compartilham oxigênio com Ti ocasionado um crescimento das vacâncias de oxigênio. Presumidamente, isso favorece a quebra das ligações Ti-O resultando na aceleração do processo de transformação [1]. Exemplos de alguns desses íons são $\mathrm{Cu}^{2+}, \mathrm{Co}^{2+}, \mathrm{Fe}^{2+}$ e $\mathrm{Li}^{+}$. Íons com raios pequenos, mas com valência maiores do que 4 , por exemplo $\mathrm{P}^{5+}, \mathrm{S}^{6+}{\mathrm{e} \mathrm{Mo}^{6+}}^{6}$ apesar de entrarem na estrutura de forma substitucional, reduzem a concentração das vacâncias de oxigênio e retardam a transformação da anatase em rutilo. Os íons com grandes raios, por exemplo, $\mathrm{Sr}^{2+}, \mathrm{PO}_{4}^{-} \mathrm{e} \mathrm{SO}_{4}{ }^{2-}$ são intersticiais e retardam a mudança de fase [40].

Cátions quadrivalentes (tais como $\mathrm{Si}^{4+}$, raio iônico $\mathrm{r} \sim 0,41$ $\AA$, para número de coordenação $\mathrm{NC}=6$ [65]) não podem entrar na estrutura anatase $\left(\mathrm{Ti}^{4+}, \mathrm{r} \sim 0,64 \AA\right.$ para $\left.\mathrm{NC}=6[65]\right)$, mas podem envolver partículas de titânia e, assim, evitar o contato direto, crescimento de grão e a transformação de fase $\mathrm{A} \rightarrow \mathrm{R}[1,52]$.

$\mathrm{Na}$ Tabela III estão compilados resultados de alguns estudos sobre os efeitos de diversos tipos de impurezas nas transformações do $\mathrm{TiO}_{2}$ [40]. Merece destaque o íon $\mathrm{W}^{6+}$ com $85 \%$ de formação da fase anatase a temperatura de $900{ }^{\circ} \mathrm{C}(3 \mathrm{~h})$.

Inúmeras pesquisas têm sido realizadas para melhorar a estabilidade térmica da titânia, sendo a dopagem com íons apontada como um método eficaz. No entanto, a aplicação de $\mathrm{TiO}_{2}$ em cerâmica ainda é limitada porque os íons de metais alcalinos e alcalino-terrosos presentes no esmalte favorecem a transição de fase $\mathrm{A} \rightarrow \mathrm{R}$ [66]. Também no caso dos substratos de vidro, que contêm cátions como $\mathrm{Na}^{+}, \mathrm{K}^{+}$, $\mathrm{Ca}^{2+}, \mathrm{Ba}^{2+}$ e $\mathrm{B}^{3+}$, a estabilidade térmica reduzida é devida à formação de vacâncias de oxigênio e o favorecimento da inclusão de cátions na interface esmalte-titânia. Essas vacâncias permitem o transporte de átomos dentro da estrutura anatase em alta temperatura e aceleram a transição de fase $\mathrm{A} \rightarrow \mathrm{R}$. Além disso, a cerâmica requer temperaturas entre 1000 e $1200{ }^{\circ} \mathrm{C}$ e nestas condições a fase majoritária é rutilo [52].

Telhas fotocatalíticas foram preparadas através da pulverização de $\mathrm{TiO}_{2}$ sobre a cerâmica com tratamento térmico em temperatura relativamente baixa. No entanto, esse procedimento leva à baixa resistência ao desgaste e uma vida-útil limitada. Assim, o desenvolvimento de uma maneira eficaz de se obter a estabilidade na titânia a altas temperaturas e com boa resistência pode se fazer pela utilização destes dopantes [66].

Estudos realizados com adições de $\mathrm{V}_{2} \mathrm{O}_{5}$ até $10 \%$ em massa, a titânia diminui a temperatura de transformação e a área específica significativamente, acelerando a transformação $\mathrm{A} \rightarrow \mathrm{R}$. Ao aumentar a quantidade de $\mathrm{V}_{2} \mathrm{O}_{5}$ há uma menor área superficial específica a uma determinada temperatura [64].

$\mathrm{O}$ uso de dopantes de $\mathrm{Si}, \mathrm{P}$ e $\mathrm{Zr}$ na titânia revela uma transição evidente de $\mathrm{A} \rightarrow \mathrm{R}$ após tratamento térmico a $800^{\circ} \mathrm{C}$. Isso demonstra que a modificação pode efetivamente inibir o crescimento de cristal e atrasar a transição. A boa estabilidade térmica é atribuída à adição de $\mathrm{Si}, \mathrm{P}$, e íons de Zr. Por um lado, esses íons podem combinar-se com uma parte de $\mathrm{O}^{2-}$ do $\mathrm{TiO}_{2}$ para formar $\mathrm{Zr}-\mathrm{O}$ e Si-O, que têm maior energia de ligação do que a ligação Ti-O da anatase [66]. Assim, o efeito dominante de uma impureza/dopante de inibir a fase rutilo atua evitando o crescimento do cristalito e não

Tabela III - Relação de íons dopantes e fases presentes após tratamento térmico. Fonte: [40].

[Table III - Relation of dopants and phases present after heat treatment. Source: [40].]

\begin{tabular}{|c|c|c|c|c|}
\hline \multirow{2}{*}{ Impureza } & \multicolumn{2}{|c|}{$\begin{array}{c}\text { Tratamento térmico } \\
3 \mathrm{~h} \mathrm{a} 800^{\circ} \mathrm{C} \\
\end{array}$} & \multicolumn{2}{|c|}{$\begin{array}{c}\text { Tratamento térmico } \\
3 \text { h a } 900^{\circ} \mathrm{C} \\
\end{array}$} \\
\hline & $\%$ Anatase & $\%$ Rutilo & $\%$ Anatase & $\%$ Rutilo \\
\hline $\mathrm{TiO}_{2}(99,9 \%)$ & 100 & 0 & 18 & 82 \\
\hline $1 \mathrm{~mol} \% \mathrm{Cu}^{2+}$ & 100 & 0 & 0 & 100 \\
\hline $1 \mathrm{~mol} \% \mathrm{Co}^{2+}$ & 79 & 21 & 0 & 100 \\
\hline $1 \mathrm{~mol} \% \mathrm{Fe}^{3+}$ & 98 & 2 & 0 & 100 \\
\hline $1 \mathrm{~mol} \% \mathrm{Mo}^{6+}$ & 84 & 16 & 4 & 96 \\
\hline $1 \mathrm{~mol} \% \mathrm{~W}^{6+}$ & 100 & 0 & 85 & 15 \\
\hline $5 \mathrm{~mol} \% \mathrm{Sr}^{+2}$ & 100 & 0 & 100 & 0 \\
\hline
\end{tabular}


favorecendo a transformação $\mathrm{A} \rightarrow \mathrm{R}$ termodinamicamente. Em temperaturas altas, os cristalitos de anatase tendem a crescem até $14,3 \mathrm{~nm}\left(700{ }^{\circ} \mathrm{C}\right)$, mas a estrutura cristalina pode ainda permanecer inalterada, demonstrando que as interações da superfície podem retardar a transformação, assim como o crescimento [38]. Por outro lado, Si, P, Zr podem formar algum tipo de encapsulamento para os grãos de $\mathrm{TiO}_{2}$, que é eficaz para reduzir o efeito de metais alcalinos e alcalino-terrosos (presentes na composição das fritas) na transição de fase [66].

É relatado que a adição de $\mathrm{Zn}^{2+}$ pode reforçar a fotoatividade da titânia significativamente, e pode atrasar a transformação da fase $\mathrm{A} \rightarrow \mathrm{R}$ a $700^{\circ} \mathrm{C}$. Também a adição de solução de ácido fosfórico a suspensão de titânia, obtidos por sol-gel altera a transformação de fase $\mathrm{A} \rightarrow \mathrm{R}$ para as altas temperaturas. A área superficial específica e a energia da band-gap do $\mathrm{TiO}_{2}$-P (titânia dopada com fosfato) aumenta com o teor de fosfato, mas diminuiu com o aumento da temperatura (calcinação). A oxidação do fenol em $\mathrm{TiO}_{2}$ puro é menos ativa que $\mathrm{TiO}_{2}-\mathrm{P}$ com teor de fosfato $<3 \mathrm{wt} \%$ [3].

Em trabalhos recentes, $\mathrm{TiO}_{2}$ dopado com $\mathrm{Zn}$ numa composição igual a $0,1 \%$ em mol e em Fe igual a $2 \%$ em mol, foi preparado pela rota sol-gel e calcinado a $500{ }^{\circ} \mathrm{C}$. A degradação fotocatalítica obtida foi, respectivamente, $81 \%, 98 \%$ e $43 \%$ para titânia não dopada, dopada com Zn e dopada com Fe. A dopagem com Zn promove uma redução do tempo necessário para atingir $50 \%$ de degradação de aproximadamente $3 \mathrm{~h}$ para apenas $40 \mathrm{~min}$. No entanto, a dopagem com ferro leva a uma diminuição da eficiência de fotodegradação. A dopagem com Fe também apresenta apenas a fase anatase, o tamanho da partícula obtido é menor que da titânia pura. No entanto, há uma diminuição na atividade fotocatalítica. Esse comportamento pode estar relacionado com a propensão que o pó tem de aglomerarse quando dopado com $\mathrm{Fe}$, promovendo uma diminuição da área superficial. A diminuição da cristalinidade também foi observada o que também pode contribuir para o comportamento apresentado [18].

Trabalhos com codopantes $\mathrm{Ga}, \mathrm{Al}$, Sc relatam a influência no crescimento de cristalito, na band-gap, na atividade fotocatalítica, e na estabilidade da fase anatase das soluções sólidas da titânia, $\mathrm{Ti}_{1-2 \mathrm{x}} \mathrm{Nb}_{\mathrm{x}} \mathrm{M}_{\mathrm{x}} \mathrm{O}_{2}$ (onde $\mathrm{M}$ pode ser $\mathrm{Ga}, \mathrm{Al}$ e Sc e x a fração). A solução sólida $\mathrm{x}$ depende do co-dopante $M$, ou seja, $x=0,15-0,20$ para $M=G a$ e $A l$, e $\mathrm{x}=0,33$ para $\mathrm{M}=\mathrm{Sc}$. $\mathrm{A}$ atividade fotocatalítica das soluções sólidas $\left(\mathrm{Ti}_{0,80} \mathrm{Nb}_{0,10} \mathrm{M}_{0,10} \mathrm{O}_{2}\right)$ codopado com $\mathrm{M}=\mathrm{Sc}, \mathrm{Ga}, \mathrm{Al}$ aumentam nessa ordem. A temperatura de transformação de fase depende do tipo de codopante e seu deslocamento para temperaturas mais altas, destaca-se na ordem de $\mathrm{M}=\mathrm{Ga}, \mathrm{Al}$, e Sc. Aalteração induzida da atividade fotocatalítica é atribuída a capacidade de absorção de luz do $\mathrm{TiO}_{2}$ fotocatalisador e taxa de transferência interfacial. O tipo de dopante e da formação de solução sólida podem influenciar na estrutura da superfície e na taxa de recombinação (elétron/buraco) no tempo de vida e comportamento dos portadores de carga. A formação de anatase através da substituição de Ti por $\mathrm{Nb}$ e outros codopantes do bloco 3A: Ga ou $\mathrm{Al}$ são eficazes na melhora da atividade fotocatalítica em comparação com o bloco 3B (Sc), devido ao aumento da cristalinidade de anatase e alta área de superfície específica $\left(\geq 100 \mathrm{~m}^{2} / \mathrm{g}\right)$. [6].

A adição de sílica $(30 \% \mathrm{~mol})$ na titânia melhora a estabilidade térmica para a fase anatase, aumenta a fotoatividade enquanto atrasa a transformação de fase $\mathrm{A} \rightarrow \mathrm{R}\left(700{ }^{\circ} \mathrm{C}\right)$. Este aumento da atividade fotocatalítica de sílica-titânia em nanocompósitos é devida a presença predominante da fase anatase, impedimento do crescimento de grãos, redução do tamanho de cristalito, aumento da energia na band-gap, redução na taxa de recombinação de elétrons e buracos durante a irradiação UV [67-69].

A utilização de dopantes como a sílica e nanopartículas de boehmita $(\mathrm{AlO}(\mathrm{OH}))$ tornam a fase anatase estável a temperatura de $1000{ }^{\circ} \mathrm{C}$. A maior estabilidade térmica foi encontrada com menor teor de titânia (entre 13 e $36 \%$ em massa) e maior teor de sílica/boehmita. Isso mostra que a sílica e nanopartículas de boehmita são eficazes para melhorar a estabilização térmica da fase anatase em comparação com a titânia pura. Obtém-se ainda melhor estabilidade térmica à medida que se substitui parcialmente a sílica como fonte de alumina [52].

Resultado similar com adição de sílica como dopante foi observado partindo-se de um alvo de rutilo (67\%) e com dopagem de até 33\% com sílica. Nesse caso, obteve-se a estabilidade da fase anatase via aplicação por sputtering e tratamento térmico de $1000{ }^{\circ} \mathrm{C}$. Com percentuais de até $15 \%$ de sílica, a fase rutilo se desenvolve juntamente com a anatase. Entretanto, para teores de sílica entre 15 e $33 \%$ a formação da fase rutilo é fortemente inibida e somente a anatase é obtida. O percentual ideal foi verificado com o teor de 33\% de sílica nos filmes de titânia [40].

A sensibilidade da titânia pode ainda ser melhorada pela adição de dopantes como o Nb, Cr, Sn, Pt, Zn, Al, La, e Y. Os efeitos mais importantes da adição destes dopantes estão relacionados em aumentar a condutividade, retardar a transformação da fase $\mathrm{A} \rightarrow \mathrm{R}$ e reduzir o crescimento de grãos [3]. Além dos trabalhos para manter a estabilidade térmica da titânia, muitas pesquisas estão sendo realizadas a fim de avaliar o desempenho fotocatalítico da titânia para funcionar sob condições de luz diurna, porque há muito mais energia produzida pela luz solar no regime visível em comparação com a luz UV [70].

\section{CONSIDERAÇÕES FINAIS}

A fotocatálise dos semicondutores envolve a formação de pares elétron-buraco, iniciando-se por excitação dos elétrons da banda de valência para a banda de condução. Entre os semicondutores, o $\mathrm{TiO}_{2}$ é o mais amplamente estudado devido principalmente à sua não-toxicidade e baixo custo em comparação com outros óxidos de metais fotocatalisadores. $\mathrm{O} \mathrm{TiO}_{2}$ pode ser produzido comercialmente através de dois processos: sulfatação ou cloretação.

A reação de fotocatálise na anatase acontece a um comprimento de onda de $388 \mathrm{~nm}$ (band-gap de 3,2 eV), contudo, a taxa de reação fotocatalítica depende da 
absorção da radiação do fotocatalisador. Da irradiação solar total, apenas $5 \%$ tem energia suficiente para causar efetiva fotossensibilização. A importância da fotocatálise está relacionada à transformação de substâncias orgânicas poluentes em substâncias inofensivas.

A fase anatase não é estável a altas temperaturas, transformando-se irreversivelmente em rutilo, fase pouco fotoativa. Inibir esta transformação de fase é importante para a aplicação em cerâmicas tradicionais que passam por temperaturas tipicamente acima de $800^{\circ} \mathrm{C}$. A transformação de fase $\mathrm{A} \rightarrow \mathrm{R}$ ocorre em uma faixa de temperatura variável, dependente de parâmetros relacionados com a natureza do material e o tratamento térmico.

Para inibir essa transformação, a utilização de dopantes influencia na cinética da transformação. Vários dopantes catiônicos têm sido empregados na transformação da fase e podem contribuir para a otimização da atividade fotocatalítica de produtos cerâmicos submetidos a temperaturas altas durante seu processamento.

\section{AGRADECIMENTOS}

Os autores agradecem ao Conselho Nacional de Desenvolvimento Científico e Tecnológico (CNPq, Brasil) e à Fundação para a Ciência e a Tecnologia (FCT, Portugal) pelo auxilio financeiro à pesquisa.

\section{REFERÊNCIAS}

[1] D. A. H. Hanaor, C. C. Sorrell, J. Mater. Sci. 46 (2011) 855.

[2] G. S. Mcnulty, Norm V Int. Conf. (2007) 1.

[3] D. P. Macwan, P. N. Dave, S. Chaturvedi, J. Mater. Sci. 46 (2011) 3669.

[4] J. B. Naceur, M. Gaidi, F. Bousbih, R. Mechiakh, R. Chtourou, Current Appl. Phys. 12 (2012) 422.

[5] J. Fazenda, in:, Tintas \& Vernizes: Ciência e Tecnologia (2009) 340-345.

[6] M. Hirano, T. Ito, J. Phys. Chem. Solids 72 (2011) 661.

[7] M. P. Seabra, R. R. Pires, J. A. Labrincha, Chem. Eng. J. 171 (2011) 692.

[8] J. M. F. Navarro, in: CSIC (Ed.), El Vidrio, $3^{\text {rd }}$ Ed., Madrid (2003) 104-127.

[9] S. Teixeira, E. F. U. Carvalho, H. G. Riella, A. M. Bernardin, in: Qualicer, Castellon (2008) 115-122.

[10] E. Sánches, Cerâm. Ind. 2 (1997) 32.

[11] J. Rodriguesa, A. M. Bernardin, in: Qualicer, Castellón (Espanha) (2010) 1-8.

[12] A. Durán, R. Hevia, in: Cyted (Ed.), Introducción a los Esmaltes Cerámicos (2002) 34.

[13] A. A. Neto, Departamento Nacional de Produção Mineral, Sumário Mineral: Titânio, Brasília (2011).

[14] A. Maia, Departamento Nacional de Produção Mineral, Balanço Mineral 2001: Titânio, Brasília (2001).

[15] C. A. M. Baltar, J. A. Sampaio, M. C. Andrade, CETEM, Minerais de Titânio, Rio de Janeiro (2005).

[16] R. N. Shreve, J. A. Brink, in: Indústrias De Processos
Químicos (1980) 346-348.

[17] I. Piwoński, K. Kądzioła, A. Kisielewska, K. Soliwoda, M. Wolszczak, K. Lisowska, N. Wrońska, A. Felczak, Appl. Surface Sci. 257 (2011) 7076.

[18] M. P. Seabra, I. M. M. Salvado, J. A. Labrincha, Ceram. Int. 37 (2011) 3317.

[19] S. A. Mayén-Hernández, G. Torres-Delgado, R. Castanedo-Pérez, J. Márquez Marín, M. Gutiérrez-Villarreal, O. Zelaya-Angel, Solar Energy Mater. Solar Cells 91 (2007) 1454.

[20] N. Yao, K. Lun Yeung, Chem. Eng. J. 167 (2011) 13.

[21] A. I. Kontos, A. G. Kontos, D. S. Tsoukleris, G. D. Vlachos, P. Falaras, Thin Solid Films 515 (2007) 7370.

[22] S. Jin, F. Shiraishi, Chem. Eng. J. 97 (2004) 203.

[23] B. K. Kaleji, R. Sarraf-Mamoory, S. Sanjabi, Reaction Kinetics, Mechanisms Catalysis 103 (2011) 289.

[24] M. Bellardita, M. Addamo, A. D. Paola, G. Marcì, L. Palmisano, L. Cassar, M. Borsa, J. Hazardous Mater. 174 (2010) 707.

[25] S. M. Gupta, M. Tripathi, Chinese Sci. Bull. 56 (2011) 1639.

[26] D. L. Liao, B. Q. Liao, J. Photochem. Photobiol. A: Chem. 187 (2007) 363.

[27] A. L. Castro, M. R. Nunes, A. P. Carvalho, F. M. Costa, M. H. Florêncio, Solid State Sci. 10 (2008) 602.

[28] A. A. Bernardes, M. C. S. Bulhosa, F. F. Gonçalves, M. G. Montes, D. Oca, Química Nova 34 (2011) 1343.

[29] U. Diebold, Surface Sci. Rep. 48 (2003) 53.

[30] X. Zhao, Q. Zhao, J. Yu, B. Liu, J. Non-Crystalline Solids 354 (2008) 1424.

[31] B. Jiang, J. M. Zuo, N. Jiang, M. O'Keeffe, J. C. H. Spence, Acta Crystallographica, Section A, Foundations of Crystallography 59 (2003) 341.

[32] J. L. Morais, "Estudo da Potencialidade de Processos Oxidativos Avançados, Isolados e Integrados com Processos Biológicos Tradicionais para Tratamento de Chorume de Aterro Sanitário", UFPR (2005).

[33] A. Fujishima, T. N. Rao, D. A. Tryk, J. Photochem. Photobiol. C: Photochem. Rev. 1 (2000) 1.

[34] S. Amemiya, Three Bond Technical News 31 (2004) 25.

[35] L. Zhao, M. Han, J. Lian, Thin Solid Films 516 (2008) 3394.

[36] G. T. Saleiro, S. L. Cardoso, R. Toledo, J. N. F. Holanda, Cerâmica 56, 338 (2010) 162.

[37] M. Shang-Di, W. Y. Ching, Phys. Rev. B 51 (1995) 13023.

[38] B. Chen, H. Zhang, B. Gilbert, J. Banfield, Phys. Rev. Lett. 98 (2007) 106103.

[39] H. Zhang, J. F. Banfield, J. Phys. Chem. B 104 (2000) 3481.

[40] A. O. Silva, "Estudo da Obtenção de Filmes de Anatásio Utilizando Rf-magnetron Sputtering", UFSC (2000).

[41] S. Pascoali, "Obtenção e Caracterização de Filmes de $\mathrm{TiO}_{2}$ Depositados sobre Cerâmica de Revestimento via Magnetron Sputtering DC", UFSC (2007).

[42] M. F. Hossain, S. Biswas, T. Takahashi, Y. Kubota, A. Fujishima, Thin Solid Films 517 (2008) 1091. 
[43] A. Y. Shan, T. I. M. Ghazi, S. A. Rashid, Appl. Catalysis A: General 389 (2010) 1.

[44] L. Andronic, D. Andrasi, A. Enesca, M. Visa, A. Duta, J. Sol-Gel Sci. Technol. 58 (2010) 201.

[45] R. F. P. Nogueira, W. F. Jardim, Química Nova 21 (1998) 69.

[46] G. Li, L. Chen, M. E. Graham, K. A. Gray, J. Molecular Catalysis A: Chem. 275 (2007) 30.

[47] U. I. Gaya, A. H. Abdullah, J. Photochem. Photobiol. C: Photochem. Rev. 9 (2008) 1.

[48] K. A. Dornelles, “Absortância Solar de Superfícies Opacas", UNICAMP (2008).

[49] L. Bouna, B. Rhouta, M. Amjoud, F. Maury, M.-C. Lafont, A. Jada, F. Senocq, L. Daoudi, Appl. Clay Sci. 52 (2011) 301 .

[50] M. C. Hidalgo, S. Sakthivel, D. Bahnemann, Appl. Catalysis A: General 277 (2004) 183.

[51] E. Rego, J. Marto, P. S. Marcos, J. A. Labrincha, Appl. Catalysis A: General 355 (2009) 109.

[52] M. Hofer, D. Penner, J. Eur. Ceram. Soc. 31 (2011) 2887.

[53] J. Chen, C. Poon, Building and Environment 44 (2009) 1899.

[54] M. E. Q. Lacey, W. N. Schirmer, Ambiênce 4 (2008) 309.

[55] J. V. S. Melo, G. Trichês, Building and Environment 49 (2012) 117.

[56] B. Ruot, A. Plassais, F. Olive, L. Guillot, L. Bonafous, Solar Energy 83 (2009) 1794.

[57] M. Fassier, N. Chouard, C. S. Peyratout, D. S. Smith, H. Riegler, D. G. Kurth, C. Ducroquetz, M. A. Bruneaux, J. Eur. Ceram. Soc. 29 (2009) 565.

[58] L. Xiong, W. Sun, Y. Yang, C. Chen, J. Ni, J. Colloid Interface Sci. 356 (2011) 211.

[59] A. Mills, A. Lepre, N. Elliott, S. Bhopal, I. P. Parkin, S. A. O’Neill, J. Photochem. Photobiol. A: Chem. 160 (2003) 213.

[60] M. D. O. Melo, L. A. Silva, J. Braz. Chem. Soc. 22 (2011) 1399.

[61] B. Huber, A. Brodyanski, M. Scheib, A. Orendorz, C.
Ziegler, H. Gnaser, Thin Solid Films 472 (2005) 114. [62] C. Guillard, H. Lachheb, A. Houas, M. Ksibi, E. Elaloui, J. Herrmann, J. Photochem. Photobiol. A: Chem. 158 (2003) 27.

[63] O. Carp, C. L. Huisman, A. Reller, Progr. Solid State Chem. 32 (2004) 33.

[64] E. C. Bucharsky, G. Schell, R. Oberacker, M. J. Hoffmann, J. Eur. Ceram. Soc. 29 (2009) 1955.

[65] L. H. V. Vlack, in: E. Blucher (Ed.) "Princípios de Ciência dos Materiais" (1970) p. 427.

[66] Z. Zeng, C. Peng, Y. Hong, Y. Lu, J. Wu, J. Am. Ceram. Soc. 93 (2010) 2948.

[67] V. S. Smitha, K. A. Manjumol, K. V. Baiju, S. Ghosh, P. Perumal, K. G. K. Warrier, J. Sol-Gel Sci. Technol. 54 (2010) 203.

[68] E. Arpaç, F. Sayilkan, M. Asiltürk, P. Tatar, N. Kiraz, H. Sayilkan, J. Hazardous Mater. 140 (2007) 69.

[69] J. Feltrin, "Estabilização a Elevadas Temperaturas da Fase Anatase com Partículas Submicrométricas de $\mathrm{SiO}_{2}$ ”, UFSC (2012).

[70] E. Arpaç, F. Sayilkan, M. Asiltürk, P. Tatar, N. Kiraz, H. Sayilkan, J. Hazardous Mater. 140 (2007) 69.

[71] D. Gumy, C. Morais, P. Bowen, C. Pulgarin, S. Giraldo, R. Hajdu, J. Kiwi, Appl. Catalysis B: Environmental 63 (2006) 76.

[72] J. Chen, S. C. Kou, C. S. Poon, Building and Environment 46 (2011) 1827.

[73] S. Sakthivel, M. V. Shankar, M. Palanichamy, B. Arabindoo, V. Murugesan, J. Photochem. Photobiol A: Chemistry 148 (2002) 153.

[74] L. Jing, S. Li, S. Song, L. Xue, H. Fu, Solar Energy Mater. Solar Cells 92 (2008) 1030.

[75] O. Ruiz, F. Sanmiguel, C. Gargori, F. Galindo, G. Monrós, Cerâm. Ind. (2009) 7.

[76] D. S. Tsoukleris, A. I. Kontos, P. Aloupogiannis, P. Falaras, Catalysis Today 124 (2007) 110.

[77]R. M. R.Pires, "Optimização Industrial de Revestimentos Cerâmicos com Propriedades Fotocatalíticas", Universidade de Aveiro (2010).

(Rec. 13/03/2013, Rev. 28/05/2013, Ac. 02/07/2013) 